\section{Population Density Effects on Fecundity of Hippelates pusio Loew (Diptera: Chloropidae)*}

\author{
M. G. Karandinos ** and R. C. Axtell \\ Department of Entomology, North Carolina State University, \\ Raleigh, N. C. 27607 , U.S.A.
}

Received January 15, 1972

Summary. A schematic model is constructed illustrating the pathways and mechanisms of adult density effects on birth rate that have been reported to operate in various taxa of insects. With this model as a guide, experimental data were collected from laboratory populations of Hippelates pusio Loew within the range of 0.15 to 25 flies per $\mathrm{cm}^{3}$ (sex ratio 1:1), which revealed: a) that adult density did not affect oviposition rate via competition for oviposition site, b) the rates of oviposition for virgin and mated females were not significantly different, and c) density did not affect frequency of copulation to a degree detectable in the hatchability of eggs. These data and previous knowledge on the reproductive biology of Hippelates pusio indicate that the birth rate of this species is independent of adult density, within then density range investigated.

\section{Introduction}

The effect of population density on birth rate is a major parameter in the dynamics of animal populations. Data from experiments with many species of insects have shown that the rate of population increase is frequently density dependant. The rate of oviposition plotted against increasing density of adults commonly gives 1 of 2 types of curves: Drosophila or Allee. In the Drosophila-type the rate of oviposition is highest at the lowest density and decreases as density increases. In the Allee-type the rate of oviposition is low at the lowest densities, highest at some intermediate density and decreases at greater densities. Curves intermediate between these 2 types may occur. Mathematical models of increasing sophistication have been constructed to express these density dependent relationships. Watt $(1960,1968)$ has critically reviewed the subject, provided extensive references and developed a new mathematical model.

\footnotetext{
* Paper no. 3651 of the Journal Series of North Carolina State Agricultural Experiment Station. Research partially supported by Training Grant ES 00069 from the National Institute of Environmental Health Sciences.

** Present address: Department of Entomology, University of Wisconsin, Madison, Wisconsin 53706, U.S.A.
} 


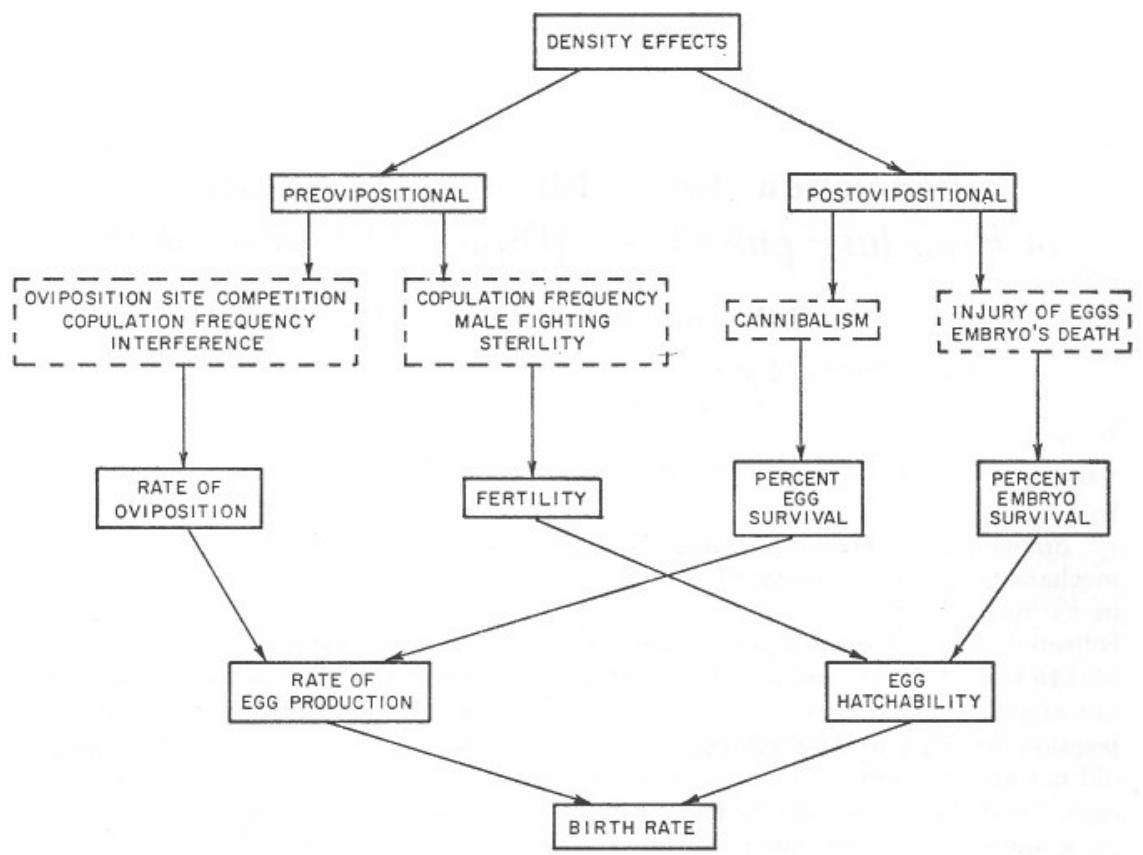

Fig. 1. A schematic model for the analysis of adult density effects on birth rate in insect populations

This report presents data from laboratory experiments on the apparent absence of an effect of adult density on the birth rate of the chloropid gnat Hippelates pusio Loew. We have attempted to consider the various pathways and mechanisms by which adult density might affect the birth rate (number of newly hatched offspring per female per unit time) of an experimental population of adults (Fig. 1). The effects associated with the two major pathways are: 1 . Preovipositional (on the adults) which become expressed in the rate of oviposition and the egg fertility rate and 2. postovipositional (on the eggs) which become expressed in the egg and embryo survival rates. The behaviorial and physiological mechanisms which may be operating are shown in the broken-lines boxes. The birth rate is a function of the rate of egg production and egg hatchability which are themselves functions of both pre- and postovipositional factors.

\section{Materials and Methods}

The $H$. pusio were from colonies (maintained at $27^{\circ} \mathrm{C}, 55$ percent relative humidity and continuous light) which were established from adult individuals collected in North Carolina in 1963. The larvae were reared in a mixture of CSMA 
(Chemical Specialities Manufacturers Association) medium and vermiculite. The adults' food consisted of dried beef blood, honey, strained prunes, and yeast. Details of rearing and handling were described by Axtell (1964) and were modifications of the techniques of Bay and Legner (1964).

The experiments were conducted at $30^{\circ} \mathrm{C}, 55$ percent relative humidity and 320 foot candle continuous light. Adults, one day old at the beginning of the experiments, were used in a 1:1 sex ratio at various densities. The flies were sexed while anesthetized with carbon dioxide.

Two sizes $\left(76 \mathrm{~cm}^{3}\right.$ and $\left.12.8 \mathrm{~cm}^{3}\right)$ of cylindrical transparent plastic containers were the experimental units. The large ones $(3.6 \mathrm{~cm}$ height $\times 5.2 \mathrm{~cm} \mathrm{diam}$. $)$ had 2 diametrically opposite ventilation openings ( $0.9 \mathrm{~cm}$ diam.; 100 mesh screen) midway on the side of the container and a third hole $(0.6 \mathrm{~cm}$ diam., 100 mesh screen $)$ in the center of the cover of the container. The flies had access to water provided by a wet piece of cellucotton resting on the latter screened port. The cellucotton was covered with a small plastic vial to retard evaporation. Food was provided by 2 to 4 pieces $(1.5 \times 1.5 \mathrm{~cm})$ of cloth strips soaked in the standard adult food mixture and glued on the inner surface of the cover. The amount of food and the food surface was large enough to exclude the possibility of starvation or competition for food even in the highest density.

The small containers $(3.65 \mathrm{~cm}$ height $\times 2.15 \mathrm{~cm}$ diam.) had 1 ventilation opening ( $0.6 \mathrm{~cm}$ diam.; 100 mesh screen) on the side of the vial. Water was supplied through a screened opening in the cover by the same method used for the large containers. The food strips $(1.0 \times 1.0 \mathrm{~cm})$ were attached to the side wall of the vial.

In experimental studies with insects, density is usually defined as the number of individuals per some unit: Surface area, volume, number of hosts, etc. In the present work, density is defined as the number of flies (sex ratio 1:1) per unit volume. There are two possible methods for manipulating density in such experiments: 1 . varying the number of insects in a constant volume, and 2 . varying the volume with a constant number of insects. Although equal densities are obtained by these two methods, the insects do not necessarily respond in the same way. In the present work, the first method was utilized. The experiment, however, was repeated utilizing a different size container.

The large containers were used in the first experiment and the small ones in the second. The number of flies per container in the first experiment were: 50, 150, 200, $300,400,500$ and 700 . The corresponding densities were: $0.67,2.01,2.68,4.02,5.36$, 6.70 and 9.38 flies per $\mathrm{cm}^{3}$. There were 2 replications per density. The eggs were collected on the 5th, 8th, 11th, 14th and 18th day of adult life.

The number of flies per container in the second experiment were: $20,50,110$, $170,200,230,260$ and 320 . The corresponding densities were: 1.56, 3.91, 8.59, $13.28,15.36,17.97,20.31,25.00$ flies per $\mathrm{cm}^{3}$. There were 2 replications per density. The eggs were collected daily for 18 days in order to find out whether or not the density affected not only the rate of oviposition but also the shape of the oviposition curve with age.

Other experiments were conducted to elucidate possible density mechanisms operating and to determine the egg hatchability. These are described where appropriate in the subsequent sections.

\section{Results}

The total fecundity per female during the 18-day period from the first experiment is given in Fig. 2 (top line). The other lines give the egg production per female per day during the indicated collection intervals. 


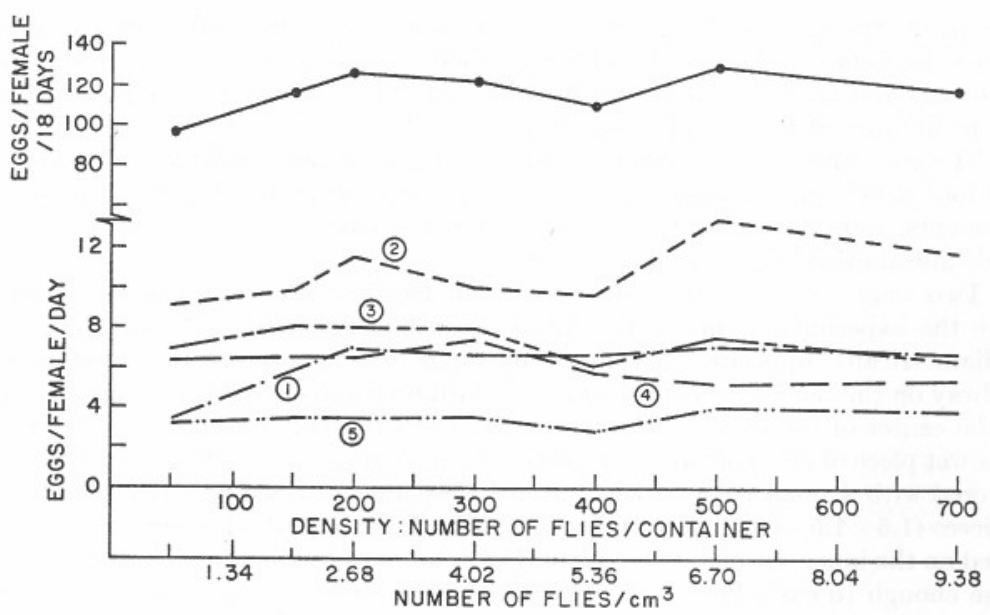

Fig. 2. Fecundity of $H$. pusio in various densities. Top line $=$ total fecundity for 18 days. Lines no. 1-5 = fecundity rates for the successive intervals of the 18 day period: 1 st 5 day, 2 nd 3 day, 3 rd 3 day, 4 th 3 day and 5 th 4 day, respectively

Except for the second collection, in which the rate of oviposition increased slightly with density, all other oviposition rates were not affected by density. In this experiment, a 14-fold range of density was attained.

In the second experiment, the density was increased to 25 flies per $\mathrm{cm}^{3}$. The whole range covered by both experiments was 37 -fold. The data from the second experiment are given in Table 1. In both experiments there was no observable trend in change of rate of oviposition with respect to density. The tendency for a lower rate of oviposition in higher densities for older age groups, was too small to affect the total fecundity trend. Calculations of the number of eggs per day per female alive showed that the slightly lower oviposition rates at high densities of older age groups was due to the higher rates of mortality at the higher densities.

The rate of oviposition was expressed as number of eggs per day per initial female instead of number of eggs per day per female alive because the emphasis in this investigation was on the reproductive potential of a population rather than on the individual. However, when the rate of oviposition was expressed as number of eggs per day per female alive and plotted as in Fig. 2, the curves were parallel and slightly above the ones illustrated. The same was true in the second experiment except at the highest densities in the oldest age groups. The total mortality during the 18-day period was about $20 \%$. Thus for the purpose of this study it made no difference in which of the two ways the rates of oviposition were expressed. 
Table 1. Rate of oviposition (eggs per female per day) of H. pusio at 8 densities $\left(12.8 \mathrm{~cm}^{3}\right.$ container)

\begin{tabular}{|c|c|c|c|c|c|c|c|c|}
\hline \multirow[t]{4}{*}{ Day } & \multicolumn{8}{|c|}{ Number of flies per $\mathrm{cm}^{3}$} \\
\hline & 1.56 & 3.91 & 8.59 & 13.28 & 15.63 & 17.97 & 20.31 & 25.00 \\
\hline & \multicolumn{8}{|c|}{ Number of flies per container } \\
\hline & 20 & 50 & 110 & 170 & 200 & 230 & 260 & 320 \\
\hline 1 & 0.00 & 0.00 & 0.00 & 0.00 & 0.00 & 0.00 & 0.00 & 0.00 \\
\hline 2 & 0.45 & 6.68 & 5.80 & 3.60 & 3.12 & 4.49 & 7.16 & 5.06 \\
\hline 3 & 32.25 & 32.88 & 37.84 & 36.57 & 37.84 & 31.53 & 35.15 & 36.44 \\
\hline 4 & 18.55 & 11.28 & 21.01 & 23.92 & 22.81 & 21.39 & 27.31 & 24.25 \\
\hline 5 & 10.35 & 13.94 & 10.90 & 10.37 & 13.36 & 9.26 & 12.23 & 8.13 \\
\hline 6 & 10.00 & 7.60 & 10.70 & 11.10 & 12.46 & 6.91 & 10.89 & 12.16 \\
\hline 7 & 7.30 & 7.86 & 9.37 & 9.17 & 8.42 & 10.09 & 9.78 & 7.53 \\
\hline 8 & 6.65 & 8.48 & 9.82 & 8.41 & 10.26 & 5.76 & 12.53 & 9.64 \\
\hline 9 & 6.20 & 6.48 & 5.18 & 6.38 & 5.32 & 6.48 & 7.05 & 6.09 \\
\hline 10 & 2.35 & 4.22 & 5.23 & 5.08 & 7.66 & 4.83 & 7.68 & 4.69 \\
\hline 11 & 6.40 & 6.80 & 5.50 & 6.76 & 4.79 & 4.30 & 4.74 & 6.25 \\
\hline 12 & 4.50 & 5.72 & 3.15 & 3.76 & 5.11 & 3.50 & 4.14 & 3.62 \\
\hline 13 & 4.15 & 4.86 & 2.77 & 4.42 & 4.56 & 3.20 & 3.92 & 1.68 \\
\hline 14 & 6.05 & 5.00 & 2.99 & 4.11 & 4.14 & 3.33 & 3.92 & 1.68 \\
\hline 15 & 3.90 & 3.90 & 3.61 & 3.31 & 4.44 & 2.48 & 3.57 & 2.57 \\
\hline 16 & 4.00 & 2.16 & 2.82 & 2.25 & 2.83 & 2.10 & 2.03 & 1.24 \\
\hline 17 & 4.80 & 4.04 & 3.13 & 3.06 & 3.01 & 2.12 & 1.46 & 2.18 \\
\hline 18 & 7.40 & 2.42 & 2.15 & 1.25 & 2.01 & 0.73 & 1.02 & 0.78 \\
\hline Total & 135.30 & 134.32 & 141.97 & 143.52 & 152.14 & 122.50 & 154.58 & 133.99 \\
\hline
\end{tabular}

Replicated experiments on oviposition were done for other purposes with only one pair of flies per small container. The mean number of eggs per female from those experiments was very close to those obtained in experiment 2 . Thus the fecundity of $H$. pusio is independent of density within the range of 0.15 to 25 flies per $\mathrm{cm}^{3}$ (166-fold range).

Preovipositional components (Fig. 1) frequently of importance in determining the density effects on oviposition are: Competition for oviposition sites, frequency of copulation, and interference (Watt, 1960). Possibly these components were operating in the $H$. pusio experimental populations but in such a way that their effects canceled each other. Therefore their joint effect would be zero. Further observations and experiments strongly suggest that this is not the case with $H$. pusio.

First, it is easily observed in the routine culturing of Hippelates in the laboratory that the gnats do not require any specific substrate for oviposition. Moreover, they have the tendency to oviposite their eggs in clusters, even when ample ovipositional area is available. Apparently oviposition by $H$. pusio is not inhibited by close proximity with each 
other or by the presence of eggs in the oviposition site, as is the case with some other insects and as the general models of Fujita (1954) and Watt (1960) anticipate. This conclusion was supported experimentally by employing two schemes for removing eggs from the cages. In one series of cages, the eggs were removed daily and in another series of identical cages with the same density, the eggs were removed at 3 to 5-day intervals. Any inhibiting effect of the presence of eggs on the subsequent rate of oviposition should be reflected as differential egg production in the two schemes. Such an effect was not observed (Table 2).

Second, there was no indication that density affected the rate of oviposition via frequency of copulation. As shown in Table 3, there was no significant difference in the oviposition rate between mated and virgin females. Therefore, even if density affected frequency of copulation, this was not a component affecting the rate of oviposition. The effect of density on frequency of copulation, however, was investigated indirectly

Table 2. No. of eggs per female $H$. pusio during indicated time intervals in an 18-day period in 2 transfer schemes. 150 flies (sex ratio $1: 1$ ) per $76 \mathrm{~cm}^{3}$ container

\begin{tabular}{lcl}
\hline Interval & $\begin{array}{l}\text { Daily } \\
\text { transfer }\end{array}$ & $\begin{array}{l}\text { Transfer at } \\
\text { indicated } \\
\text { interval }\end{array}$ \\
\hline 1st 5-day & 30.18 & 29.79 \\
2nd 3-day & 30.68 & 29.48 \\
3rd 3-day & 25.26 & 24.18 \\
4th 3-day & 17.49 & 19.53 \\
5th 4-day & 13.57 & 14.08 \\
\hline Total & 117.18 & 117.06 \\
\hline
\end{tabular}

Table 3. No. of eggs per female $H$. pusio per indicated collection from 150 virgin females and 150 females kept with equal numbers of males

\begin{tabular}{lcc}
\hline Collection & Mated & Virgin \\
\hline 1 & 2.25 & 1.90 \\
2 & 6.24 & 5.78 \\
3 & 4.20 & 3.15 \\
4 & 3.55 & 4.27 \\
5 & 4.62 & 3.71 \\
6 & 2.36 & 1.76 \\
\hline Total & 23.22 & 20.57 \\
\hline
\end{tabular}

Prob. $|t|$ (paired test) greater than observed $=0.15$. 
by determining the hatchability of eggs in four densities of young adults over the high section of the density spectrum (Table 4). The confidence intervals were computed by considering each mean as an estimate of the parameter $\mathrm{p}$ in a binomial distribution and by assuming a normal distribution for the estimator. No significant difference was found among the four means. Considering these seven records as replicates, the overall mean and the $95 \%$ interval was $71.61 \pm 2.54$. A similar interval computed from 26 records obtained in a different experiment ${ }^{1}$ with 100 flies per $76 \mathrm{~cm}^{3}$ unit at $27^{\circ} \mathrm{C}$ gave a mean of $71.17 \pm 6.35$. It is, therefore, concluded that under the experimental conditions density did not significantly affect the hatchability of eggs.

Table 4. Percent hatch of H. pusio eggs oviposited at 4 densities of adults (sex ratio $1: 1)$. Numbers in parenthesis are the number of eggs observed for hatching

\begin{tabular}{lllll}
\hline $\begin{array}{l}\text { No. flies } \\
\text { per 76 } \mathrm{cm}^{3} \text { unit }\end{array}$ & $\begin{array}{l}\text { No. flies } \\
\text { per } \mathrm{cm}^{3}\end{array}$ & \multicolumn{3}{l}{ Percent hatch } \\
\cline { 3 - 5 } & Rep. 1 & Rep. 11 & Mean ${ }^{\mathrm{a}}$ \\
\hline 700 & 9.38 & $76.14(176)$ & $68.24(85)$ & $73.56 \pm 5.39$ \\
900 & 12.06 & $70.53(207)$ & $70.56(180)$ & $70.54 \pm 4.51$ \\
1100 & 14.74 & $69.23(221)$ & $73.18(261)$ & $71.37 \pm 3.92$ \\
1300 & 17.42 & - & $73.36(214)$ & $73.36 \pm 5.88$ \\
\hline
\end{tabular}

a Weighted mean and $\mathbf{9 5 \%}$ confidence interval.

Other mechanisms and pathways listed in Fig. 1 do not seem to be operating in $H$. pusio. Cannibalism by adults on their eggs is not possible since eye gnats do not have the appropriate types of mouth parts. No evidence of egg injury was observed. Male fighting may be occurring although we saw no evidence in this situation.

These data indicate that the rate of oviposition and the birth rate of $H$. pusio are independent of population density within the density range included in this investigation.

\section{Diseussion}

The pathways and mechanisms of density effects on birth rate which are illustrated in Fig. 1 are not all functioning in every insect species. Each species, depending on its own behavioral and physiological peculiarities, reflecting the evolutionary history of the species, will utilize some combination of these effects.

1 Karandinos M. G., Axtell, R. C.: Effects of aging on the fertility of Hippelates pusio, H.bishoppi and H.pallipes (Diptera: Chloropidae). Submitted to Ann. Entomol. Soc. Amer. (1972). 
Models of density effects on oviposition are bound to include many parameters since there are many components via which these effects operate. Which of these components is functioning and how, in a particular species, has to be determined. Density effects are expected to exist for insect species which require very specific oviposition sites (e.g. parasitic Hymenoptera), need copulation as a stimulus for oogenesis and oviposition, live in habitats where mutual contact is somehow impeded, or have cannibalistic habits. In species not having these behavioral attributes, density effects are less likely to occur. Apparently this is the case with $H$. pusio.

The lack of any observable effect of adult density on the birth rate of $H$. pusio does not mean that the rate of increase of this species is density independent, since density effects may be manifested in other stages of the life cycle. There is evidence from laboratory experiments that larval competition does take place (Legner, 1966). It is also known that parasites (Legner, 1968) and physical environmental conditions (Hummadi and DeFoliart, 1967; Karandinos and Axtell, $1967 \mathrm{a}, \mathrm{b})$ affect the rate of increase of Hippelates. Whether these and/or other factors operate in a density-dependent fashion and/or under field conditions is not known.

\section{References}

Axtell, R. C.: Laboratory rearing of Hippelates pusio and H.bishoppi. (Diptera: Chloropidae). J. Elisha Mitchell Scient. Soc. 80, 225 (1964).

Bay, E. C., Legner, E. F.: Quality control in the production of Hippelates collusor (Tsnd.) for use in the search and rearing of their natural enemies. Proc. Amer. Mosquito Control Ass. 19, 403-410 (1964).

Fujita, H.: An interpretation of the changes in type of population density effect upon the oviposition rate. Ecology 35, 253-257 (1954).

Hummadi, M. K., DeFoliart, G. R.: Biology of Hippelates pallipes and H. bishoppi (Diptera: Chloropidae) in Wisconsin. J. Med. Ent. 4, 66-70 (1967).

Karandinos, M. G., Axtell, R. C.: Temperature effect on the immature stages of Hippelates pusio, H.bishoppi and H.pallipes (Diptera: Chloropidae). Ann. entomol. Soc. Amer. 60, 1055-1062 (1967 a).

Karandinos, M. G., Axtell, R. C.: Effect of temperature on the longevity, fecundity, and activity of adult Hippelates pusio, H. bishoppi, and H. pallipes (Diptera: Chloropidae). Ann. entomol. Soc. Amer. 60, 1252-1255 (1967 b).

Legner, E. F.: Competition among larvae of Hippelates collusor (Diptera: Chloropidae) as a natural control factor. J. Econ. Ent. 59, 1315-1321 (1966).

Legner, E. F.: Parasite activity related to ovipositional responses in Hippelates collusor. J. Econ. Ent. 61, 1160-1163 (1968).

Watt, K. E. F.: The effect of population density on fecundity in insects. Can. Ent. 92, 674-695 (1960).

Watt, K. E. F.: Ecology and resource management. New York: MeGraw-Hill Co. 1968.

Dr. R. Axtell

Department of Entomology

North Carolina State University

Baleigh, North Carolina 27607, U.S.A. 